\title{
Propofol for endoscopy in Canada: A sleepy or a slippery slope?
}

\author{
Rakesh Bhandari MD¹, Paul C Adams MD², Editor-in-Chief
}

$\mathrm{D}_{\mathrm{s}}^{\mathrm{r}}$ Rakesh Bhandari is an Assistant Professor in the Department of Anesthesia and Perioperative Medicine at the University of Western Ontario, London, Ontario. Outside of the operating room, he has an interest in the Management of Anesthetic Care, and has direct experience in the use of propofol during endoscopic retrograde cholangiopancreatography.

"The Propofol wave which seemed at one point to be about to break over the USA like a tsunami has yet to reach the shore" (1).

PA: It has been reported that $17 \%$ of gastroenterology (GI) units in the United States use propofol for endoscopy and $43 \%$ of units considered its use in 2005 (1). The advantages of this approach may include rapid induction and recovery, and improved patient and physician comfort. However, these benefits come at a cost and many GI units in Canada are satisfied with their current use of benzodiazepines and narcotics. Can you review the characteristics of propofol?

RB: Propofol is an isopropylphenol that is

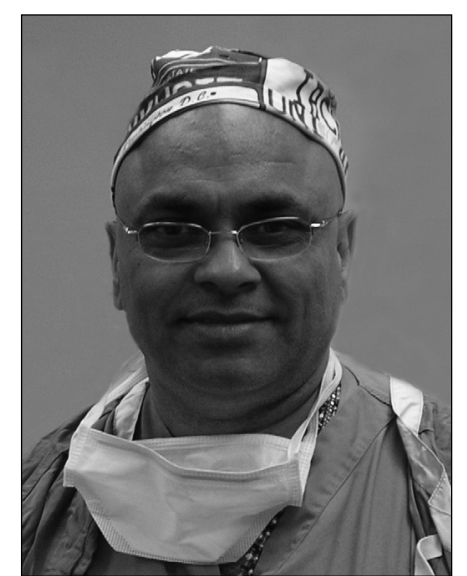

Dr Rakesh Bhandari is an Assistant Professor in the Department of Anesthesia and Perioperative Medicine at the University of Western Ontario, London, Ontario choice for conscious sedation in ambulatory anesthesia. Generally, a continuous infusion intravenous dose of propofol $(25 \mu \mathrm{g} / \mathrm{kg} / \mathrm{min}$ to $100 \mu \mathrm{g} / \mathrm{kg} / \mathrm{min})$ is used to induce amnesia and light sedation. Patients usually recover within $5 \mathrm{~min}$ to $10 \mathrm{~min}$ after discontinuation of this infusion. If a clinician chooses to use adjunct medications such as midazolam and fentanyl, this recovery phase may be prolonged. Along with this sedative hypnotic effect, propofol provides some antiemetic and antipruritic effects. It has no analgesic properties.

The most common side effect of propofol is peripheral vasodilation resulting in hypotension. Peripheral vasodilation is primarily due to a decrease in the sympathetic outflow from the central nervous system. There may be some negative inotropic effects of propofol from the decrease in intracellular calcium availability. There is a risk of bradycardia-related death during propofol administration which has been reported to be 1.4 in 100,000 patients. Propofol also produces dose-dependent depression of ventilation and causes apnea in approximately $25 \%$ to $35 \%$ of patients. Other coinduction drugs and narcotics, such as midazolam and fenadministered intravenously as 1\% solution for the induction of anesthesia or as an intravenous sedation agent. It was introduced in the mid 1980s and has been used for hundreds of millions of procedures worldwide. Propofol is presumed to exert its effect through its interaction with gammaaminobutyric acid receptors, the principal inhibitory neurotransmitters in the brain. When administered intravenously, propofol is rapidly cleared from the circulation. Its clearance takes place by redistribution possibly into the lungs and more importantly in the liver. Only $0.3 \%$ of the dose is excreted, unchanged, in the urine. The elimination half-life of propofol is approximately $0.5 \mathrm{~h}$ to $1.5 \mathrm{~h}$. This drug has a very fast clearance and therefore can be administered as a continuous infusion or as multiple boluses without any accumulative effects. Propofol has been used as the drug of choice for the induction of anesthesia and also for intravenous conscious sedation.

In healthy adults, the general anesthesia intravenous induction or deep sedation doses of propofol is $1.5 \mathrm{mg} / \mathrm{kg}$ to $2.5 \mathrm{mg} / \mathrm{kg}$, which should be decreased in elderly or debilitated patients by up to $50 \%$. Consciousness returns within $10 \mathrm{~min}$ to 15 min after administration of these doses have been discontinued, and provided no or very small doses of coadjuncts such as fentanyl, midazolam, etc, are used.

Quick recovery without much residual sedation, and low incidence of nausea and vomiting, make propofol the drug of tanyl, may enhance this ventilatory depression. Other minor side effects include pain on injection that can be decreased by concurrent or pre-emptive use of intravenous xylocaine. Propofol also promotes bacterial growth; therefore, it cannot be kept for more than $4 \mathrm{~h}$ after opening the drug. There are no known reversal agents available for propofol.

PA: Can you comment on bolus and infusions of propofol? How soon does a patient recover? Are they able to drive home?

RB: For short procedures, like upper and lower GI endoscopy, an infusion of propofol ranging from $25 \mu \mathrm{g} / \mathrm{kg} / \mathrm{min}$ to $100 \mu \mathrm{g} / \mathrm{kg} / \mathrm{min}$ could be used, resulting in a cooperative patient with amnesia for endoscopy. This provides awakening and orientation within 5 min to 10 min after discontinuation of the infusion. Propofol can be used as a single large bolus followed by multiple small boluses depending on the duration of the procedure. A typical dose used for this technique would be $0.5 \mathrm{mg} / \mathrm{kg}$ to $1 \mathrm{mg} / \mathrm{kg}$ body weight followed by small doses of $10 \mathrm{mg}$ to $20 \mathrm{mg}$ intravenous propofol. For brief procedures just lasting $5 \mathrm{~min}$ to $10 \mathrm{~min}$, I personally prefer to give a bolus followed by small doses as required. It is not advisable for the patient to drive home after propofol administration.

PA: Is it possible to have pain while unconscious from propofol? RB: Yes, it is possible to have pain while the patient is unconscious from propofol because it provides no analgesia.

\footnotetext{
${ }^{1}$ Department of Anesthesia and Perioperative Medicine; ${ }^{2}$ Department of Gastroenterology, London Health Sciences Centre, London, Ontario Correspondence and reprints: Dr Rakesh Bhandari, Department of Anesthesia and Perioperative Medicine, London Health Sciences Centre, 339 Windermere Road, London, Ontario N6A 5A5. Telephone 519-663-3384, fax 519-663-3161, e-mail raki@rbhandari.com
} 
PA: Who should administer propofol in the endoscopy room? In the United States and other countries, there seems to be a model developing for specialized nurses to administer propofol $(2,3)$.

RB: As quoted from the product insert for propofol (Diprivan, AstraZeneca Canada Inc):

"For general anesthesia or monitored anesthesia care or sedation propofol injectable emulsion should be administered only by persons trained in the administration of general anesthesia and not involved in the conduct of the surgical/diagnostic procedure."

The American College of Gastroenterology has petitioned the Food and Drug Administration to change the package insert for propofol to allow its use by people not trained in airway management. In Canada, we have no certified registered nurse anesthetists (CRNAs) to provide administration of propofol in the endoscopy room. The Canadian Anesthesiologists' Society (CAS) formed a task force on anesthesia assistants in 1995. The CAS guidelines (4) stated that:

- An anesthesia assistant would usually be a respiratory technologist because they have airway management skills and training in the use of drugs;

- They will work under the direct supervision of an anesthesiologist; and

- Their role is supportive and does not involve independent practice.

After 15 years, this is still a work in progress, and a big question is who will pay for these positions. The task force concluded that anesthesiologists would retain the responsibility for patient care and that the anesthesiologist and anesthesia assistant would work as a team to provide the best care. The task force also determined that there is a place for assistants in the delivery of anesthesia services due to the expanding nature of anesthesia services inside and outside the operating room. The CAS also sees no role for the independent practice of anesthesia by CRNAs. Currently, there is no system for training of CRNAs in Canada. Also, I would like to say that if there is a serious shortage of nursing personnel in other areas of nursing care, how can we expect registered nurses to take on more responsibility in different areas of medical practice? From my personal experience, I think using the CRNA model may not be cost-effective because one anesthesiologist performs the workload of approximately 2.5 to three CRNAs. This seems to be more of a political issue than an actual patient care issue. I also hear there is talk of using nurse practitioners for performing endoscopies because there is a backlog of patients who need upper and lower GI procedures. Personally, as a patient, I would not like to have a nongastroenterologist performing an endoscopy and making very important decisions affecting my life.

PA: There seems to be a shortage of anesthesiologists in Canada. Is it likely that we could find an MD anesthesiologist who would choose to work full time in an ambulatory GI unit? What is the anesthesiology fee for an endoscopic procedure in Canada?

RB: There does seem to be a shortage of anesthesiologists in Canada. As I have already mentioned, for the past 15 years, the CAS has been involved in developing and implementing guidelines for anesthesia assistants because they anticipated a shortage of anesthesiologists due to the lack of insight in government policies. In my opinion, this anesthesia assistant model could be used to provide intravenous sedation for GI endoscopies. There may be some anesthesiologists who are interested in providing anesthesia care for endoscopies. The current Ontario Health Insurance Plan fee for anesthesia care of endoscopic procedures is approximately $\$ 100$.

PA: Enthusiasts hope that propofol will greatly increase throughput because of its short recovery time. This is offset by the costs of anesthesia care. There may also be enhanced patient safety with this approach. How do you see the balance of benefits of costs in a Canadian health care environment?

RB: The answer to this question is yes and no, which depends on your current practice. If you require a longer period of time to get the patient adequately comfortable for the procedure, then I think propofol administration by trained personnel may decrease the amount of time required to reach the level where the patient is comfortable. Although there may not be any cost savings involved, there may be a higher degree of patient and endoscopist comfort level. I also think that the time may come when patients would be willing to pay from their own pocket for this procedure to be comfortable.

\section{REFERENCES}

1. Byrne MF, Baillie J. Nurse-assisted propofol sedation: The jury is in! Gastroenterology 2005;129:1781-2.

2. Tohda G, Higashi S, Wakahara S, Morikawa M, Sakumoto H, Kane T. Propofol sedation during endoscopic procedures: Safe and effective administration by registered nurses supervised by endoscopists. Endoscopy 2006;38:360-7.

3. Rex DK, Heuss LT, Walker JA, Qi R. Trained registered nurses/endoscopy teams can administer propofol safely for endoscopy. Gastroenterology 2005;129:1384-91.

4. Canadian Anesthesiologists' Society. Guidelines to the practice of anesthesia, revised 2005. <http://www.cas.ca/members/sign_in/ guidelines/practice_of_anesthesia/Guidelines.pdf $>$ (Version current at October 30, 2006) 


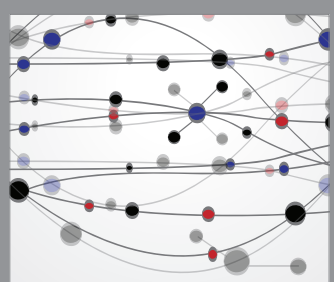

The Scientific World Journal
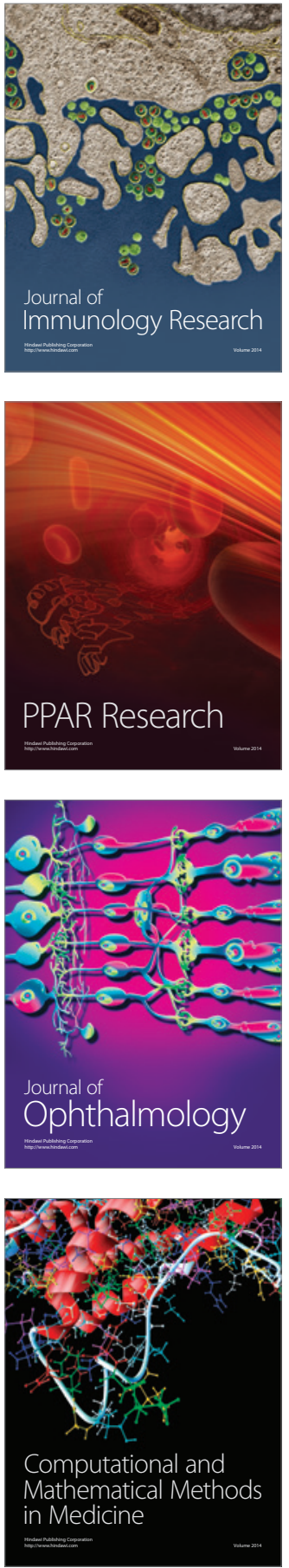

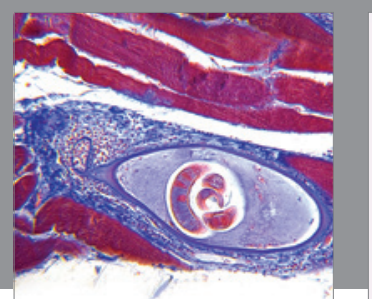

Gastroenterology Research and Practice

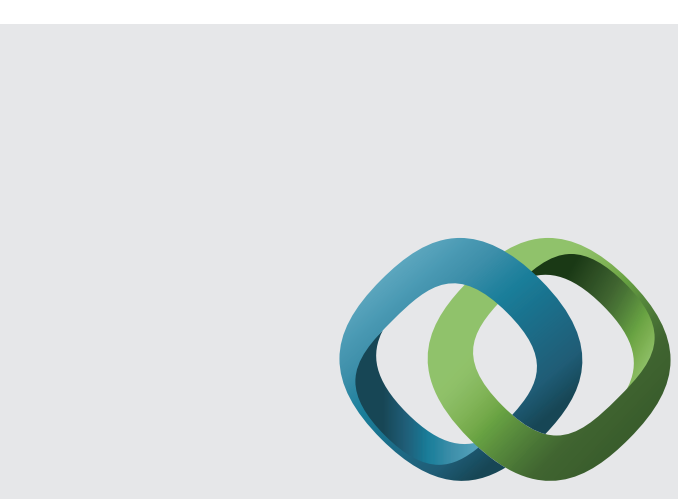

\section{Hindawi}

Submit your manuscripts at

http://www.hindawi.com
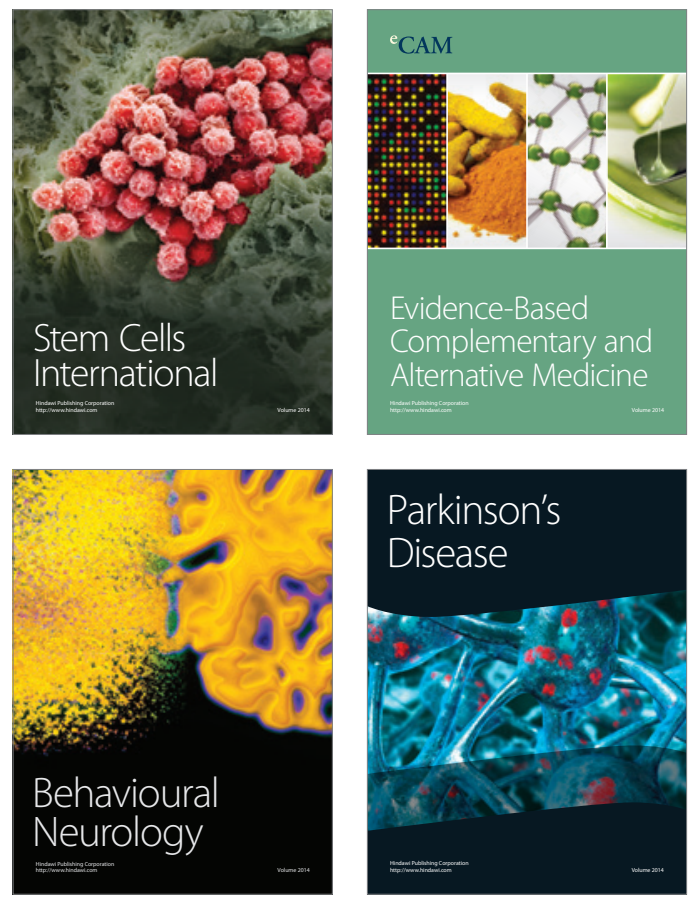
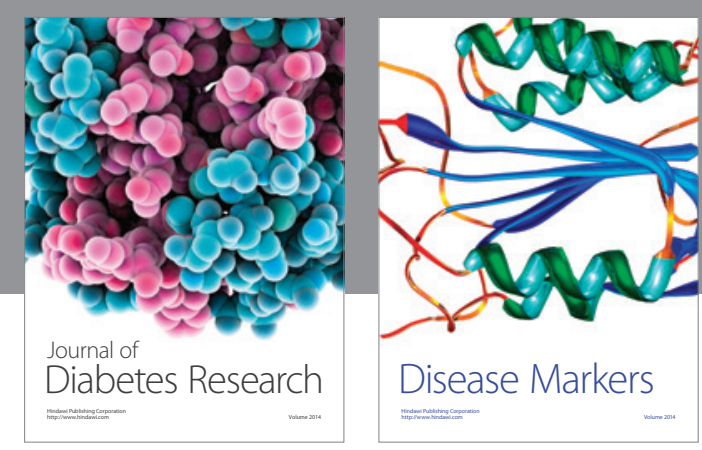

Disease Markers
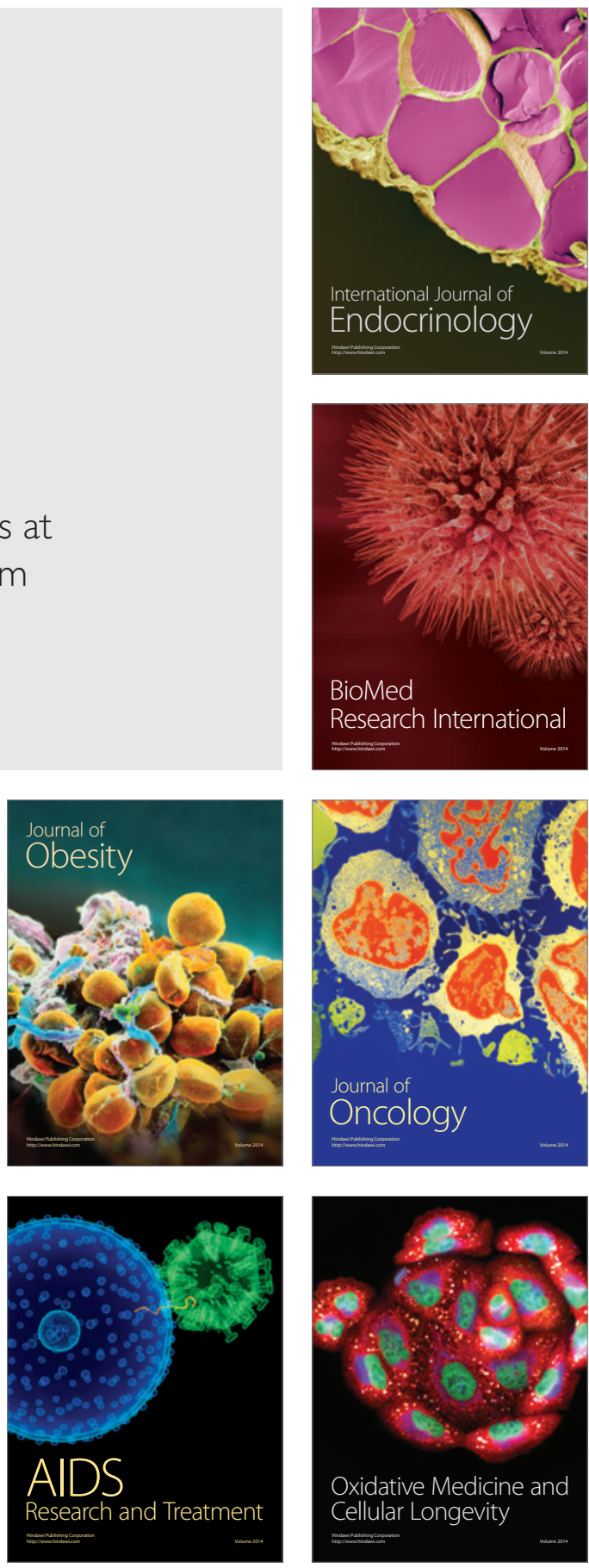